\title{
Improved assessment of aortic 3D blood flow with combined k-t accelerated 3D CINE bSSFP \& 4D flow MRI
}

\author{
Kelly B Jarvis ${ }^{1,3^{*}}$, Can Wu', Shivraman Giri ${ }^{2}$, Susanne Schnell ${ }^{1}$, Alex J Barker ${ }^{1}$, Jeremy D Collins ${ }^{1}$, James C Carr ${ }^{1}$, \\ Michael Markl ${ }^{1,3}$
}

From 19th Annual SCMR Scientific Sessions

Los Angeles, CA, USA. 27-30 January 2016

\section{Background}

To determine hemodynamic parameters from 4D flow MRI, vessel boundaries are typically depicted by calculating a 3D phase contrast MR angiogram (PC-MRA) from 4D flow magnitude and flow images. However, this approach is limited by 1) low blood-tissue contrast of the magnitude images and 2) velocity weighting of PC-MRA may not fully depict areas of slow or swirling (vortex) flow. As a result, 3D flow analysis at the aortic root has been challenging due to the presence of vortex flow distal to the aortic valve. Fast 3D balanced steady state free precession (bSSFP) time-resolved MRI sequences offer a promising alternative, providing anatomical images with improved blood-tissue contrast. The goal of this feasibility study was to integrate results from 3D CINE bSSFP with 4D flow MRI to improve the segmentation of vessel anat- omy and thus 3D blood flow assessment compared to standard segmentation using PC-MRA data alone.

\section{Methods}

Non-contrast free-breathing 3D CINE bSSFP and 4D flow MRI were acquired in the aorta $(\mathrm{n}=6$ controls: age $=56$ $+/-11$ yrs, 1 female) with identical spatial resolution (Figure 1) and $\mathrm{k}-\mathrm{t}$ acceleration with reduction factor $\mathrm{R}=5$ to reduce overall scan times. Multiple 3D CINE bSSFP scans were averaged to mitigate breathing effects and then interpolated along the temporal domain for integration with 4D flow. 3D segmentation of the aorta included 1) standard approach using the PC-MRA and 2) new approach utilizing 3D CINE bSSFP MRI averaged over the cardiac cycle. The resulting aortic segmentations were used to mask the $4 \mathrm{D}$ flow velocity data for analysis. Systo-

Table 1: Scan Parameters and Results

\begin{tabular}{|c|c|c|c|c|c|c|c|c|c|}
\hline \multirow[b]{2}{*}{ Protocol } & \multicolumn{5}{|c|}{ Scan Parameters } & \multicolumn{4}{|c|}{ Flow Analysis } \\
\hline & $\begin{array}{l}\text { Spatial } \\
\text { Resolution } \\
\left(\mathrm{mm}^{3}\right)\end{array}$ & $\begin{array}{l}\text { Temporal } \\
\text { Resolution } \\
\text { (ms) }\end{array}$ & $\begin{array}{l}\text { Scan } \\
\text { Time } \\
\text { (s) }\end{array}$ & $\begin{array}{l}\text { Respiratory } \\
\text { control }\end{array}$ & $\begin{array}{l}\text { Imaging } \\
\text { Acceleration }\end{array}$ & $\begin{array}{l}\text { Vortex } \\
\text { Grade }\end{array}$ & $\begin{array}{l}\text { Peak } \\
\text { Velocity } \\
\text { (m/s) }\end{array}$ & $\begin{array}{l}\text { Net Flow } \\
\text { (ml/cycle) }\end{array}$ & $\begin{array}{l}\text { Forward } \\
\text { Flow } \\
\text { (ml/cycle) }\end{array}$ \\
\hline $\begin{array}{l}\text { 3D CINE } \\
\text { bSSFP MRI }\end{array}$ & $\begin{array}{l}2.1-2.3 x \\
2.1-2.3 x \\
2.5\end{array}$ & 51 & $39-56$ & $\begin{array}{l}3 \text { scans } \\
\text { averaged }\end{array}$ & $k-t R=5$ & $1.5+/-0.5$ & $1.4+/-0.3$ & $78.1+/-22.2$ & $79.8+/-23.1$ \\
\hline 4D flow MRI & $\begin{array}{l}2.1-2.3 x \\
2.1-2.3 x \\
2.5\end{array}$ & $39-40$ & $\begin{array}{l}315- \\
570\end{array}$ & $\begin{array}{l}\text { navigator } \\
\text { gating }\end{array}$ & $k-t R=5$ & $0+1-0$ & $1.4+/-0.3$ & $74.3+/-19.1$ & $74.7+/-19.3$ \\
\hline
\end{tabular}

Figure 1

'Department of Radiology, Northwestern University, Chicago, IL, USA

Full list of author information is available at the end of the article 


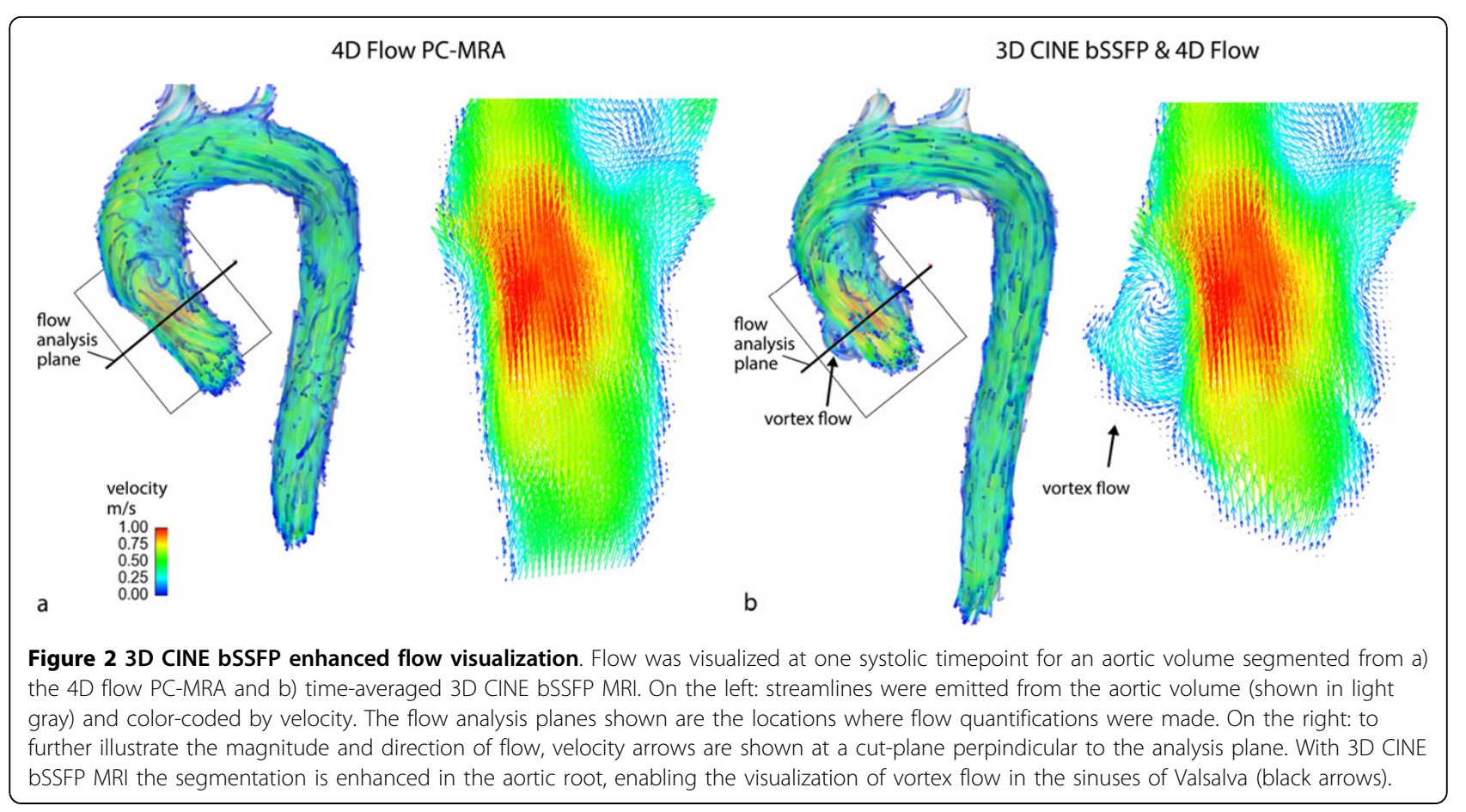

lic blood flow was visualized using streamlines emitted from the aortic volume and graded for the appearance of vortex flow in the sinuses of Valsalva $(0=$ none, $1=$ mild, $2=$ moderate). Flow and peak velocity were quantified in the sinuses and compared between methods using the paired Wilcoxon signed rank test.

\section{Results}

3D CINE bSSFP MRI enabled the segmentation of the aorta, including areas of vortex flow distal to the aortic valve in the sinuses of Valsalva (figure 2). With the standard segmentation approach using the PC-MRA, vortex flow in the sinuses could not be reliably visualized for any subject. In contrast, the new approach utilizing combined 3D CINE bSSFP and 4D flow data enabled the visualization of either mild or moderate vortex flow in the sinuses for all subjects. As expected, peak velocity remained the same between segmentation techniques. Also, flow results were comparable $(\mathrm{p}>0.05)$ (Figure 1$)$.

\section{Conclusions}

We have developed $k$ - $t$ accelerated 3D CINE bSSFP MRI compatible for post-processing combination with 4D flow MRI. This technique shows great potential to improve the hemodynamic assessment of patients with aortic disease by providing an accurate segmentation of vessel walls in areas such as the aortic root that are difficult to assess using standard methods. Further study is needed to optimize the scan protocol, test alternative PC-MRA calculations and explore time-resolved segmentation using 3D CINE bSSFP MRI.

\section{Authors' details}

'Department of Radiology, Northwestern University, Chicago, IL, USA.

${ }^{2}$ Siemens Healthcare, Chicago, IL, USA. ${ }^{3}$ Department of Biomedical Engineering, Northwestern University, Chicago, IL, USA.

Published: 27 January 2016

doi:10.1186/1532-429X-18-S1-P232

Cite this article as: Jarvis et al:: Improved assessment of aortic 3D blood flow with combined k-t accelerated 3D CINE bSSFP \& 4D flow MRI. Journal of Cardiovascular Magnetic Resonance 2016 18(Suppl 1):P232.
Submit your next manuscript to BioMed Central and take full advantage of:

- Convenient online submission

- Thorough peer review

- No space constraints or color figure charges

- Immediate publication on acceptance

- Inclusion in PubMed, CAS, Scopus and Google Scholar

- Research which is freely available for redistribution
C Biomed Central 